Editorial

\title{
Novos desafios dos Sistemas de Informação no contexto atual das organizações
}

\section{New challenges of Information Systems in the current context of organizations}

\author{
António Abreu' ${ }^{1}$ João Vidal Carvalho ${ }^{1}$, Álvaro Rocha ${ }^{2}$ \\ aabreu@iscap.ipp.pt, cajvidal@iscap.ipp.pt, amrocha@dei.uc.pt \\ ${ }^{1}$ Politécnico do Porto/ISCAP/CEOS.PP, Rua Jaime Lopes Amorim, s/n, 4465-004 S. Mamede de Infesta, \\ Portugal. \\ ${ }^{2}$ Universidade de Coimbra, Departamento de Engenharia Informática, Pólo II - Pinhal de Marrocos, 3030- \\ 290 Coimbra, Portugal.
}

DOI: 10.17013/risti.3o.o

\section{Introdução}

A Informação assume hoje em dia, uma importância crescente, sendo uma porta aberta para o futuro. Ela torna-se fundamental para as organizações, na conceção e adoção de novas tecnologias, na exploração das oportunidades de investimento e ainda na planificação de toda a atividade organizacional.

A inovação nos Sistemas de Informação (SI), surge como um domínio estratégico de investigação para suportar as organizações através de todo o processo de desenvolvimento e crescimento, e como resposta aos novos desafios associados ao contexto atual de extrema competitividade. A adoção de metodologias e aplicações inovadoras nos SI, devem naturalmente, começar através de um processo criativo de identificação de oportunidades e necessidades da sociedade, prosseguindo para o seu desenvolvimento e implementação, até desencadear na criação de valor e consequentemente na melhoria da eficácia, eficiência e desempenho das organizações.

Nestecontexto,osSIassumemumpapeldeterminante, sendohojereconhecidospelasociedade, nomeadamente a comunidade científica e as organizações, como um instrumento basilar para a concretização da aquisição e transferência de conhecimento e, concomitantemente, para a modernização, reforma e transformação dos processos organizacionais. 
Assim, o número trinta da RISTI (Revista Ibérica de Sistemas e Tecnologias de Informação) debruça-se sobre um conjunto diversificado de metodologias e aplicações inovadoras em Sistemas e Tecnologias de Informação, que vão desde a análise, recolha e disponibilização de dados, passando por novas metodologias e estratégias na educação baseadas em novos recursos educativos emergentes, até às aplicações web.

O conjunto de oito artigos publicados neste número da RISTI resultou de um escrutínio efetuado pelos membros da comissão científica sobre os cinquenta e cinco trabalhos apresentados pelos autores, oriundos quinze do Brasil, oito de Espanha, sete de Portugal, sete do Equador, cinco da Colômbia, cinco da Argentina, três do Peru, três do México, um de Cuba e um da República Dominicana, correspondendo a uma taxa de aceitação de 14,5\%.

\section{Estrutura}

Estando a revista empenhada em proporcionar aos seus leitores, uma forma ágil e prática na leitura desta edição, considerou-se ser pertinente apresentar em primeiro lugar, as contribuições que exibem metodologias inovadoras no ensino aprendizagem, na adoção de medidas formais, informais e técnicas de segurança da informação em ambiente institucional e na resposta dos SI que emergem dos constantes desafios dos novos sistemas ciber-físicos. Finalmente, os últimos artigos, embora se apresentem como altamente inovadores, são de âmbito mais genérico. Assim:

No primeiro artigo, os autores descrevem um estudo que apresenta os efeitos da metodologia de aprendizagem móvel (modalidade de e-Learning), em que a aprendizagem ocorre através de dispositivos eletrónicos móveis, no ensino universitário a partir da revisão da literatura científica nas bases de dados Web of Science e Scopus.

O segundo artigo expõe uma investigação que teve como objetivo identificar o tipo de pressões que influenciam a adoção de medidas formais, informais e técnicas de Segurança da Informação em universidades públicas brasileiras, quando têm o desafio de divulgar conhecimento, protegendo informações de pesquisa e dados privados. A investigação, para além de uma exaustiva revisão bibliográfica, teve como amostra um conjunto de gestores e profissionais de Segurança da Informação das universidades. Analisados os dados, os autores concluíram que a adoção de medidas técnicas e informais é influenciada principalmente por pressões normativas, enquanto medidas formais são adotadas devido a pressões coercitivas.

No terceiro artigo, é descrito o desenvolvimento de um modelo de interoperabilidade semântica para a simulação de toda a gestão da rede logística, nas suas diversas fases de distribuição. A simulação de toda a gestão da rede logística tem a grande vantagem de preservar a independência dos membros da cadeia, sendo capaz de reutilizar os simuladores existentes. $\mathrm{O}$ artigo apresenta uma ferramenta conceptual, baseada numa rede de ontologias, que suporta as tarefas de modelação e composição da simulação de toda a gestão da rede logística, nas suas diversas fases de distribuição de forma a garantir a interoperabilidade semântica dos seus membros.

O quarto artigo apresenta um estudo que descreve os novos desafios associados aos SI, que emergem dos novos sistemas ciber-físicos, que combinam ambiente físico com digital, aos modelos de negócio e serviços das organizações. As empresas devem organizar 
o seu portefólio de SI de modo a conceber processos inteligentes que respondam rápida e criativamente aos novos desafios de trabalho e mercado. Segundo os seus autores, uma arquitetura aberta, ágil, ativa e permeável ao contexto será muito útil.

$\mathrm{O}$ quinto artigo descreve um mecanismo de controlo para evitar congestionamento na transferência de informação numa rede de dados, sempre que se pretenda enviar por múltiplos pontos distintos, múltiplos destinatários, ao mesmo tempo em redes TCP/ IP, utilizando um endereço multicanal. O principal objetivo do algoritmo proposto, é evitar a perda de pacotes de informação, mantendo um equilíbrio na taxa de envio dos emissores. Além disso, o algoritmo analisa constantemente o estado de saturação dos nós do comutador e do recetor, considerando a tecnologia de armazenamento utilizada.

No sexto artigo, os autores apresentam o desenvolvimento de um sistema de recolha e disponibilização de dados sobre potenciais danos nas infraestruturas rodoviárias do Brasil. Esse trabalho, propõe um sistema capaz de realizar a recolha de dados de possíveis buracos e disponibilizá-los numa aplicação web, utilizando um sistema inteligente, um módulo eletrónico no automóvel, e outro alojado na nuvem. O sistema é composto por placas, sensores e aplicações que recolhem dados de possíveis buracos, armazenam os dados localmente e posteriormente, enviam esses dados para uma web service RESTful localizado na nuvem.

O sétimo artigo resultou de uma investigação que teve por objetivo testar a usabilidade de uma ferramenta web para investigação operacional. Os avanços nas TIC promoveram o uso de ferramentas de software como meio de apoio e complemento em sala de aula. Este trabalho, introduz por um lado, uma ferramenta web multiplataforma intuitiva que permite resolver problemas de programação linear, e que pode ser utilizada pelos alunos e, por outro, realiza um estudo de usabilidade da ferramenta para identificar itens positivos e pontos de melhoria.

O último artigo apresenta um trabalho de investigação com recurso à utilização do Facebook no contexto da doação de sangue. O espaço de relacionamento do Facebook vem redefinindo a participação social, adquirindo poder junto da população nas diversas causas sociais, incluindo a doação de sangue. Esta investigação analisou a capacidade de mobilização do Facebook e do seu potencial envolvimento social, identificando os recursos de governança e a prática da equidade social, por meio dos dados obtidos na FanPage do centro de hematologia público do Estado do Ceará - Brasil.

\section{Agradecimentos}

Termina-se esta introdução, expressando o nosso agradecimento a todos os autores e revisores envolvidos nesta edição, esperando que este número da RISTI se revele uma leitura profícua para todos os que se mobilizam em torno da problemática dos Sistemas e Tecnologias de Informação. Um agradecimento especial à AISTI, proprietária e promotora da RISTI, à Academic Journals Database, CiteFactor, Compendex, Dialnet, DOAJ, DOI, EBSCO, GALE, IndexCopernicus, Index of Information Systems Journals, ISI Web of Knowledge, Latindex, ProQuest, QUALIS, SciELO, SCImago e Scopus, entidades que têm contribuído para tornar a RISTI uma referência neste competitivo mercado das revistas científicas. 